\title{
MATERNAL PSYCHOSOCIAL STRESS AND LABOR DYSTOCIA
}

D0l: $10.36740 /$ WLek202007105

\author{
Svitlana I. Zhuk, Oksana D. Shchurevska \\ SHUPIK NATIONAL MEDICAL ACADEMY OF POSTGRADUATE EDUCATION, KYIV, UKRAINE
}

\begin{abstract}
The aim: to study the possible role of psychosocial stressors in the emergence of anomalies of childbirth, as well as to examine their nature using the example of pregnant women who have been forcefully displaced from Donetsk and Luhansk regions of Ukraine.

Materials and methods: 115 internally displaced pregnant women from Donetsk and Luhansk regions, were surveyed. All women underwent a comprehensive neuropsychological examination of their psycho-emotional status via interviews, questioning, and psychological testing (Spielberg-Haning's Situational and Personal Anxiety Scale). The following analysis of the childbirth process' nature was conducted.

Results: The prevalence of high level of situational and personal anxiety by the Spielberg-Haning's test were determined in the internally displaced women. This indicates a high level of social anxiety (stress) in these pregnant women.

Labours in women in this group can be characterized by 3 main features: rapid (precipitated) labour with high levels of obstetric traumatism (tear of perineum) and labour medicalization (EDA). The characteristics described above are due to such labour activity anomalies as hypertensive uterine dysfunction - the cases when the speed and strength of uterine contractions significantly exceed the normative parameters.

The reasons for the high level of pain in labour in displaced women could be objective and subjective factors: excessive nociceptor irritation due to cervical-uterine dysfunction and impaired individual perception of pain.

Conclusions: Chronic psychosocial stress has an impact on labour activity in displaced women. A mandatory standard for managing such pregnancy is psychological counselling and correction of the identified disorders.
\end{abstract}

KEY WORDS: stress, anxiety, internally displaced women, labor anomalies

Wiad Lek. 2020;73(7):1334-1338

\section{INTRODUCTION}

Childbirth is always associated with a physiological process that is absolutely natural for every woman, and ends with giving birth to a healthy baby. However, the anomalies of a childbirth process as a clinical and theoretical problem have not lost their relevance up to date, and still accompany $11-42 \%$ of all labours [1].

The consequences of these are an increase infectious complications risk, maternal injuries, including tear of the uterus and the perineum with subsequent development of pelvic floor muscle prolapse, bleeding, neonatal acidosis and injuries of the neonates. All around the globe the anomalies of childbirth are holding the first place among the indications for the first caesarean section, and that leads to a regular increase in the frequency of anomalies in the future. Therefore, it becomes not only a medical problem but also a social one. The negative experience of pathological labour subsequently causes deterioration of the quality of life of young women, disruption of relationships with their dearest environment; it causes conflicts in the family and arises fears for the subsequent pregnancies and childbirth, as well as leads to the complication during next pregnancy and labour. The "vicious circle" of new unresolved problems comes up again.

Mechanisms of inception and progression of child delivery include many complex interrelated psycho-neu- roendocrine processes. The prerequisites for a normal childbirth are the smooth operation of this entire system. Any violation of any link leads to complications in labour. But despite the fact that neuroendocrine regulation of contractile activity is already well studied, its psychological aspects are either debatable or simply out of the sight of researchers and clinical physicians. One of the factors that may have a serious impact on childbirth process is a stress.

Every pregnant woman is typically stressed about the changes her body undergoes in relation to pregnancy, as well as about well-being and condition of the baby inside her, upcoming labour and motherhood. These refer to the physiological pregnancy stress, which in moderate manifestations is considered to be normative. The effects of additional stressors, such as the so-called psychosocial stressors that include changes in personal life, loss of status, work, house, financial stress, etcetera, lead to additional mobilization of the body's defences and changes in the pregnant woman's behaviour in order to be able to overcome them[2]. Altogether these factors create preconditions for the complicated course of pregnancy and childbirth. Therefore, in order to improve the quality of obstetric care, its adjustment to the needs of different social groups, there is a need for a more detailed study of this issue. 


\section{THE AIM}

To study the possible role of psychosocial stressors in the emergence of anomalies of childbirth, as well as to examine their nature using the example of pregnant women who have been forcefully displaced from Donetsk and Luhansk regions of Ukraine.

\section{MATERIALS AND METHODS}

In order to achieve this goal, we surveyed 115 internally displaced pregnant women from Donetsk and Luhansk regions, who were monitored and then gave birth in the Kyiv Municipal Maternity Clinic №2. All patients were examined in accordance with the current regulations in obstetrics and gynaecology.

Inclusion criteria: single pregnancy, 37-41 weeks of gestation, absence of severe extra-genital pathology, spontaneous onset of labour.

Exclusion criteria: pregnancy as the result of assistive reproductive technologies, multiple pregnancy, $<37$ and $>41$ weeks of gestation, presence of severe extra-genital pathology, induction of labour, planned (elective) or urgent surgical delivery.

All women underwent a comprehensive neuropsychological examination of their psycho-emotional status via interviews, questioning, and psychological testing (Spielberg-Hanin's Situational and Personal Anxiety Scale). The analysis of the childbirth process' nature was conducted according to the clinical observation data, partograms and instrumental methods of research (tocography).

We formed a group of 70 women with a physiological pregnancy for the comparison purposes.

\section{RESULTS}

According to the analysis of the anamnestic data (Table 1), both groups had no significant difference as per main indicators $(p>0.05)$. In the first group $(p>0.05)$ somewhat older women pregnant with the first child, mainly with higher education and married prevailed. Significant difference between the groups was determined by social and living conditions: the women of group 1 were characterized by a high percentage of the unsettled mode of life and unsatisfactory financial situation, which became one of the causes of the corresponding psychological problems. According to several recent Cochrane reviews, these factors play important role in preventing gestational complications. The need for the correction of these factors refers to the so-called psychosocial interventions that should be addressed during pregnancy. Psychosocial intervention is "any non-pharmacological intervention conducted in a therapeutic context at the individual, family or group level" (WHO 2009) and is "focused on psychological and / or social factors rather than biological ones", and directly or indirectly changes woman's behaviour, cognition and / or emotional state $[3,4]$.

We are not capable of preventing the effects of global social factors on pregnancy and childbirth, yet we consider encouraging a partner support as an available and cost-effective method of assisting and behavioural correction during childbirth to be the golden standard of obstetric care. Regrettably, according to the obtained data, in the group of internally displaced women the partner was present during the childbirth only in every second case (versus $84.3 \%$ in the comparison group). Special attention should be paid to this fact in course of dealing with this category of patients.

The methodology for stress research in pregnant women is a highly debated issue worldwide. For example, the conventional definition of the stress hormone, e.g. cortisol, has certain features during gestation: a pregnant woman's reaction to it is not always dependent on its level; its high concentrations may be a normal value for a certain woman, and the foetus is protected from its influence by a specific placental enzyme - 11- $\beta$-hydroxysteroid dehydrogenase. Therefore, a psychological testing is most commonly used with the help of Spielberg-Haning's Situational and Personal Anxiety Scale. The level of anxiety can be considered as the level and type of stress that is important for the occurrence of pathology. The level of situational (reactive) anxiety (level of anxiety at the moment) and personal anxiety (anxiety as a stable personal characteristic) are determined. Anxiety is an acquired behavioural dysfunction that causes an individual to perceive a wide range of objectively safe events as threats, responding to them by falling into a state of anxiety [5].

Every person individually perceives and responds to the same situation as to a stressful or a non-stressful one.

Table 1. Sociodemographic characteristics of the examined groups.

\begin{tabular}{ccc}
\hline & $\mathbf{1}$ group, $\mathbf{n = 1 1 5}$ & $\mathbf{2}$ group, $\mathbf{n = 7 0}$ \\
\hline Age, years & $29,08 \pm 5,15$ & $26,5 \pm 3,6$ \\
\hline Nulliparous & $67(58,3 \%)$ & $46(65,7 \%)$ \\
\hline Multiparous, first labor & $29(25,2 \%)$ & $15(21,4 \%)$ \\
\hline Multiparous, & $19(16,5 \%)$ & $9(12,9 \%)$ \\
\hline Higher education & $89(77,4 \%)$ & $58(82,8 \%)$ \\
\hline $\begin{array}{c}\text { Secondary education, } \\
\text { incomplete higher } \\
\text { education }\end{array}$ & $26(22,6 \%)$ & $12(17,2 \%)$ \\
\hline Registered marriage & $96(83,5 \%)$ & $62(88,6 \%)$ \\
\hline $\begin{array}{c}\text { Unregistered marriage } \\
\text { Partner at birth }\end{array}$ & $19(16,5 \%)$ & $8(11,4 \%)$ \\
\hline $\begin{array}{c}\text { Satisfactory financial } \\
\text { situation }\end{array}$ & $61(53,0 \%)$ & $59(84,3 \%)$ \\
\hline $\begin{array}{c}\text { Unsatisfactory financial } \\
\text { situation }\end{array}$ & $80(69,6 \%)$ & $57(81,4 \%)$ \\
\hline $\begin{array}{c}\text { Satisfactory living } \\
\text { conditions }\end{array}$ & $35(30,4 \%)$ & $13(18,6 \%)$ \\
\hline $\begin{array}{c}\text { (own apartments) } \\
\text { condisfactory living }\end{array}$ & $12(11,4 \%)$ & $8(11,4 \%)$ \\
\hline $\begin{array}{c}\text { Unsatisfactory living } \\
\text { conditions }\end{array}$ & $13(11,3 \%)$ & $20(28,6 \%)$ \\
\hline
\end{tabular}




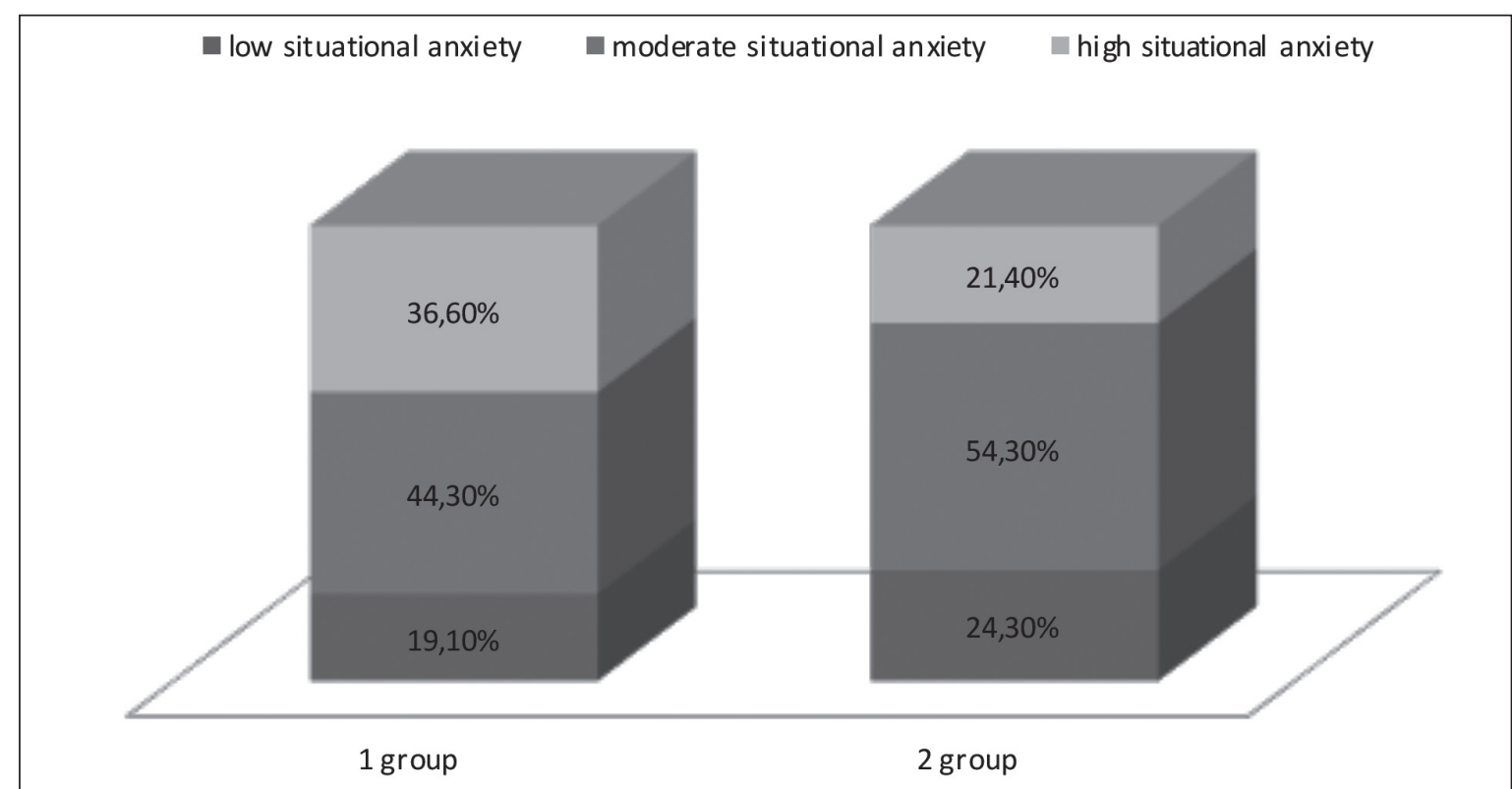

Fig. 1. Personal Anxiety Level of the examined groups

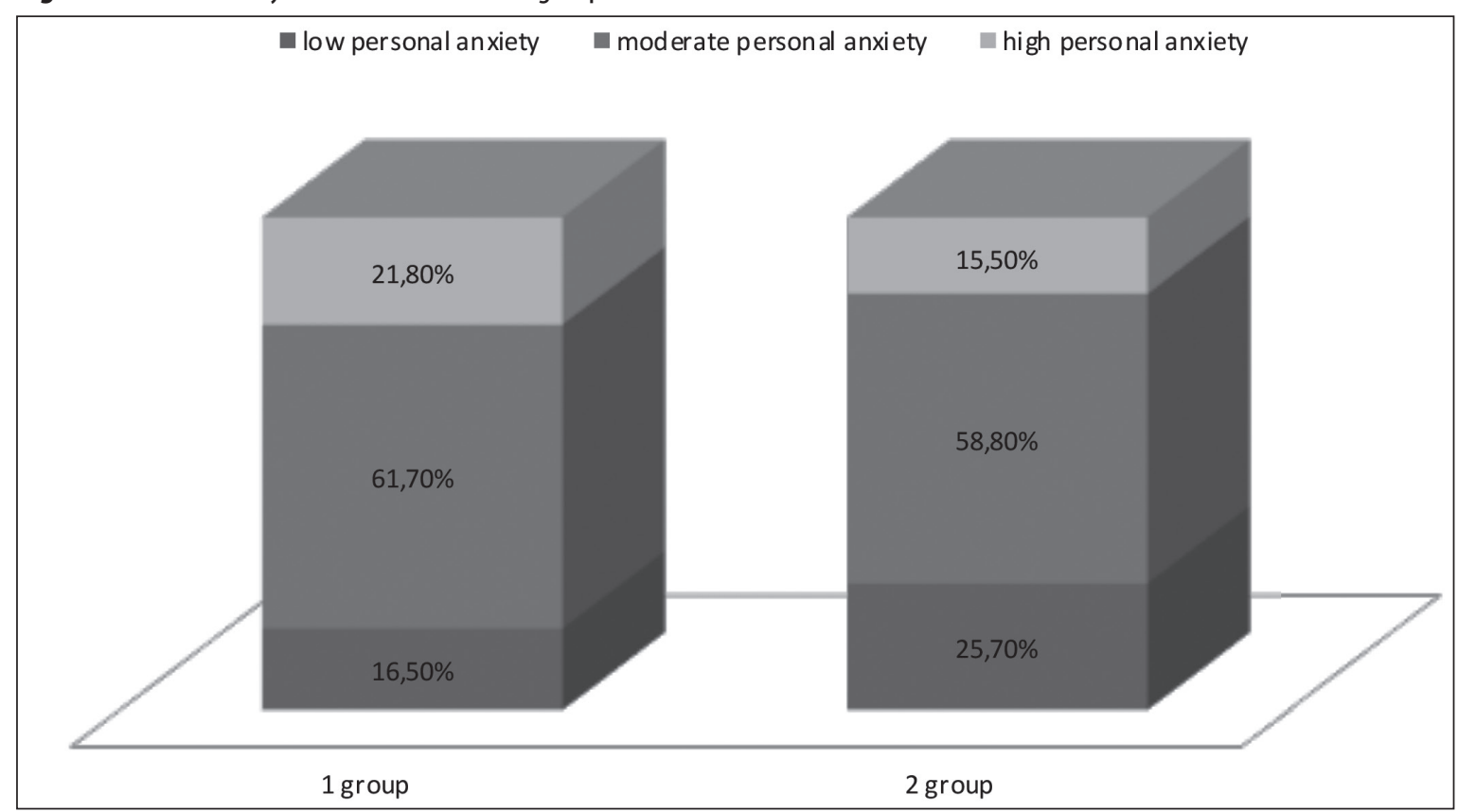

Fig. 2. Situational Anxiety Level of the examined groups

A moderate level of anxiety is a normative value for humans because it allows them to adapt to the surrounding changes. However, its severity can be detrimental, not always in line with the magnitude of the objective danger, and thus can further be transformed into a personal anxiety.

Situational (reactive) anxiety more closely reflects an individual's response to a certain threatening situation, and it is associated with social challenges in particular. It is caused by emotional experiences related to a state of uncertainty, instability, as well as nebulosity of the future, sensation of lack of support from the loved ones, etcetera. Reactive anxiety is characterized by tension, emotional anxiety, nervousness and behavioural changes. It affects the process of psychological adaptation of a pregnant woman to the very fact of pregnancy, future childbirth and the postpartum period, as well as the formation of maternal behaviour. This psychological testing does not clearly identify a particular stressor as a cause for the anxiety of patients, but it allows identifying risk groups for them to take appropriate preventive measures.

When analysing the results of the Spielberg-Haning's test, the prevalence of middle and high levels of anxiety is determined in pregnant women of both groups, especially in the group of the internally displaced women (fig.1,2). This indicates a high level of stress in these pregnant women.

Moreover, such an unfavourable structure of indicators is common for both situational and personal anxiety. Thus, it cannot be explained by just sole fact of the upcoming really stressful event - that is giving birth and subsequent motherhood. It is also a reflection of the level of social anxiety. 
According to research data, anxiety from moderate to high levels is one of the most important risk factors for development of anomalies in childbirth.

According to scientists, anxiety and fear lead to the production of stress hormones, and in pregnant women before childbirth the sensitivity to them is increased. Anxiety is accompanied by the release of catecholamines that interrupt the coordination of uterine contractions via binding $ß$-adrenoreceptors that are located in the myometrium and, therefore, slowing down the progression of labour [6,7].

Almost all the literature available for referencing this issue $[8,9,10]$ provides unidirectional data, according to which women with high levels of prenatal psychosocial stress are characterized by the complicated labour flow in the form of weakened childbirth. However, when analysing our data, we obtained completely opposite results (Table 2). For internally displace women who gave birth in our maternity clinic, the opposite pattern was typical - each $5^{\text {th }}$ case displayed rapid (precipitated) labour, and the incidence of weakness in labour in this group was 1.5 times lower than in the comparison group.

\section{DISCUSSION}

Reaction and response to any stress consists of 3 main components: emotional (disquiet, anxiety, fear), neuroendocrine (activation of the sympathoadrenal system) and behavioural. All of them are aimed at overcoming stress. But both: the action of extreme force stressors or chronic action of stressors cause the exhaustion (distress) of the body that subsequently somatises them. In women with high levels of psychosocial stress during pregnancy, we can clearly follow the said results during their labours.

Labours in women in this group can be characterized by 3 main features: rapid (precipitated) labour with high levels of obstetric traumatism (tear of perineum) and labour medicalization (EDA). The characteristics described above are due to such labour activity anomalies as hypertensive uterine dysfunction - the cases when the speed and strength of uterine contractions significantly exceed the normative parameters.

Also, this group of women was almost in 1.5 times more likely to elect epidural anaesthetics due to painful contractions than in group 2, despite the fact they had regular labour activity on admission to the maternity clinic. The reasons for the high level of pain in labour in displaced women could be objective and subjective factors. Objective factors include excessive nociceptor irritation due to established cervical-uterine dysfunction. But the main reason is an impaired individual perception of pain. A high level of anxiety amplifies it at the level of the cerebral cortex. In addition, chronic stress leads to hyper-activation of the sympathetic division of the autonomic nervous system, which lowers the threshold of pain sensitivity.

For every woman, childbirth is an extreme stressful event that requires the mobilization of all body resources. Under normal stress reactivity and stress resistance, the body switches on physiological protective mechanisms that regu- late and maintain normal labour; also natural mechanisms of anaesthesia are activated. Along with the active work of a woman in labour, the use of self-anaesthesia skills, her mobility, the availability of adequate support from a partner and medical staff, the favourable psychological factors are created to reduce individual sensitivity.

But instead of an active work displaced women avoid it by opting for passive pain management in the form of epidural anaesthesia.

In referencing the literature on the subject, we found single studies that study the hormonal regulation of emotions. In particular, Zelkowitz P., et al. in 2014 studied the relationship between the release of endogenous oxytocin during pregnancy and childbirth in women with psychosocial stress. The authors found high levels of this hormone in their blood. Endogenous oxytocin can be a buffer against the harmful effects of stress, protecting a woman from developing depressive symptoms and promoting more sensitive maternal behaviour [11]. That is, another reason for excessive labour can be the features of hormonal background in these women, but these data still need further study.

\section{CONCLUSIONS}

Labour activity in displaced women is characterized by hypertensive dysfunction with high levels of obstetric traumatism and medicalization during childbirth process. The prerequisites for its occurrence are chronic psychosocial stress, a reflection of which is a high and moderate level of anxiety. A mandatory standard for managing such pregnancy is psychological counselling and correction of the identified disorders. Given the high level of obstetric trauma in childbirth, it is necessary to foresee and provide the preventive measures in the form of remediation of inflammatory processes during pregnancy, gentle management of childbirth with the involvement of partner support and psychological support of the medical staff, the use of obstetric gels for labour and use of protective elements for the perineum.

\section{REFERENCES}

1. Beniuk V.O., Nykoniuk T.R. Kompleksnyi pidkhid do likuvannia slabkosti polohovoi diialnosti u rodil z patolohichnym perebihom preliminarnoho periodu (Ohliadova stattia) [The complex of medical arrangements, which are used in powerless labor during pathological preliminary period] .Zdorove zhenschinyi. 2016; 6: 11-15.(In Ukrainian).

2. Coussons-Read M.E. Effects of prenatal stress on pregnancy and human development: mechanisms and pathways. Obstet Med. 2013; 6(2): 52-57. doi: 10.1177/1753495X12473751

3. Hanada N., Matsuzaki M., Ota E. et al. Psychosocial and educational interventions in latent phase or early labour for improving birth outcomes. Cochrane Database of Systematic Reviews 2015, Issue 2. Art. NNo.: CD011516. DOI: 10.1002/14651858.CD011516.

4. Kobayashi S., Hanada N., Matsuzaki M. et al. Assessment and support during early labour for improving birth outcomes. Cochrane Database of Systematic Reviews 2017, Issue 4. Art.No.:CD011516. DOl:10.1002/14651858.CD011516.pub2. 
5. Noskova 0.V. Osobennosti trevozhnogo sostoyaniya zhenschin pri beremennosti i ego psihokorrektsiya [Features of the anxiety state of women during pregnancy and its psychocorrection]. Meditsinskaya psihologiya. 2008; 3:52-56..(In Russian).

6. Laursen M., Hedegaard M., Johansen C. Fear of childbirth: predictors and temporal changes among nulliparous women in the Danish National Birth Cohort. BJOG: An International Journal of Obstetrics \& Gynaecology. 2008; 115: 354-360. doi:10.1111/j.1471-0528.2007.01583.x

7. Simkin P. Dysfunctional labor: general considerations. In: Simkin P., Ancheta R. Labor Progress handbook: Early Interventions to Prevent and Treat Dystocia. West Sussex: Wiley-Blackwell; 2011p. 15-29.

8. Da Costa D., Dritsa M., Larouche J. et al. Psychosocial predictors of labor/delivery complications and infant birth weight: a prospective multivariate study. Psychosom Obstet Gynaecol. 2000;21(3):137-48.

9. Paarlberg K.M., Vingerhoets A.D., Geijn H. Maternal Stress and Labor. 2006.10.3109/9781439814697-207.

10. Dunkel Schetter C., Tanner L. Anxiety, depression and stress in pregnancy: implications for mothers, children, research, and practice. Current opinion in psychiatry. 2012; 25(2): 141-148. doi:10.1097/YC0.0b013e3283503680

11. Zelkowitz P., Gold I., Feeley N. et al. Psychosocial stress moderates the relationships between oxytocin, perinatal depression, and maternal behavior. Horm Behav. 2014 ;66(2):351-60. doi:10.1016/j.yhbeh
Work was carried out as part of the research work of the department of Obstetrics, Gynaecology and Fetal Medicine Shupyk NMAPE "Optimization of complex assessment of the fetus" ( No 011 U222466)

\section{ORCID and contributionship:}

Svitlana I. Zhuk: 0000-0003-1565-8166 A,D,E,F

Oksana D. Shchurevska: 0000-0002-7236-348X ${ }^{B, C, D, F}$

\section{Conflicts of interest.}

The Authors report no conflicts of interest.

\section{CORRESPONDING AUTHOR Oksana D. Shchurevska}

Shupyk National Medical Academy of Postgraduate Education 11 Mostitskaya st., 04074 Kyiv, Ukraine tel: +380444604554

e-mail: fetalmedic@ukr.net, oksanaschurevska@ukr.net

Received: 22.01 .2020

Accepted: 17.06 .2020

A - Work concept and design, B - Data collection and analysis, C - Responsibility for statistical analysis,

D-Writing the article, $\mathbf{E}$-Critical review, $\mathbf{F}$ - Final approval of the article 